\title{
Influencing Factors of Participating in Social Governance of Social Science Mass Organizations in Hubei Province
}

\author{
$\mathrm{Li} \mathrm{Li}$ \\ School of Literature, Law and Economics \\ Wuhan University of Science and Technology \\ Wuhan, China
}

\author{
Lihong Ruan \\ School of Literature, Law and Economics \\ Wuhan University of Science and Technology \\ Wuhan, China
}

\begin{abstract}
Social science mass organization plays an important leading role in the prosperity and development of philosophy and social sciences. This article examines the social functions and the constraints of social science mass organizations from the three dimensions of theoretical research, social services and policy support through quantitative analysis. It has made operations on the social function status and the development status of the social science mass organizations. The logistic regression analysis is used to examine the impact of the social development status on the social function. It should control the development history and location factors. And then, it can examine the influence of development mode, development scale, personnel protection and funding guarantee on the social functions of social science mass organizations.
\end{abstract}

Keywords-social science mass organizations; social governance; influencing factors; analysis

\section{INTRODUCTION}

The social science mass organizations can prosper academics, develop humanities and social sciences and promote humanism through theoretical research. The social science mass organizations can carry forward traditional culture, stimulate social vitality and enrich social life through social services. Also, the social science mass organizations can provide intellectual support, improve social governance and enhance decision-making through policy advisory. And social science mass organizations should bear the basic social functions. To serve the community is the ultimate goal of existence and development of social science mass organizations. On the whole, most of the social science mass organizations nowadays can't meet the needs of the community in theoretical research, social services and policy support. So, what has restricted the social functions of social science mass organizations? What are the limiting factors within the social science mass organizations? What is the biggest resistance? What are the external constraints? From January 2014 to June 2016, the research group selected the social science mass organizations in Hubei province as the research object. The author randomly selected the samples from 183 social science mass organizations in the form of questionnaires. And the author also distributed 70 electronic questionnaires, and 52 valid samples were recovered. In the following, the author would analyze the possible factors influencing social functions of social science mass organizations through variable design.

\section{THE VARIABLE SETTINGS}

According to the differences of the social objects targeted by social science mass organizations, such as social workers, the general public and government departments, this section examines social functions and its constraints of the social science mass organizations from three dimensions of theoretical research, social services and policy advisory.

\section{A. Dependent Variable Settings}

In this study, the operations of theoretical research can be transferred into social science mass organizations. And social science workers engaged in relevant academic activities, theoretical research, including the convening of academic conferences, published journals or books or published projects in the name of social science mass organizations. Through the preliminary correlation analysis, the author found that different social science mass organizations focused on different academic activities, and the correlation among three activities is not significant. Previous studies found that almost all of social science mass organizations held academic conferences. In the interviews, the author found that social science mass organizations didn't make a clear distinction between academic conferences and general assemblies. Taking into account of the above factors, in addition to regular academic conferences, other theoretical approach should be an important way to examine theoretical research. Therefore, the operation of theoretical research would be transferred into the publications and books and published research topics. The assignment of "yes" is 1 , and the assignment of "no" is 0.

We will transform social services into various kinds of lectures, trainings and publicity campaigns. These activities popularize social sciences, disseminate social culture and promote humanism that is aimed at the general public and providing various types of information. Through the preliminary analysis of correlation, the author find that there 
is strong correlation among the three social services $(\mathrm{p}=$ 0.000 in the following table) "Table I". And it indicates that some social science mass organizations pay attention to various forms of social services, while some social science mass organizations may neglect providing the social services for the public. In this article, it turns the operations of social service into one of three social services. The assignment of "yes" is 1 , and the assignment of "no" is 0 .

TABLE I.

CORRELATION COEFFicient of SOCIAL SERVICES INDEX (SPEARMAN)

\begin{tabular}{|c|l|l|l|l|}
\hline \multicolumn{2}{|c|}{ Lecture } & \multicolumn{1}{c|}{ Training } & \multicolumn{1}{c|}{ Social propaganda } \\
\hline \multirow{2}{*}{ Lecture } & correlation coefficient & 1.000 & $.602 * *$ & $.589^{* *}$ \\
\cline { 2 - 5 } & Sig. (bilateral) &. & .000 & .000 \\
\hline \multirow{2}{*}{ Training } & correlation coefficient & $.602 * *$ & 1.000 & $.544^{* *}$ \\
\cline { 2 - 5 } & Sig. (bilateral) & .000 &. & .000 \\
\hline \multirow{2}{*}{ Social propaganda } & correlation coefficient & $.589 * *$ & $.544^{* *}$ & 1.000 \\
\cline { 2 - 5 } & Sig. (bilateral) & .000 & .000 &. \\
\hline
\end{tabular}

It turns the operations of policy advisory in the form of providing policy advisory and intellectual support for relevant government departments through government consultation reports. Through preliminary analysis, the author found that the proportion of policy support provided by government consultation reports is very small (less than $7 \%$ ). Other forms of policy support may have been overlooked in the survey. So, it could choose the question of "How important do you think you are in government policy advisory?" in the questionnaire. As an alternative, it is a fivepoint question. "1" represents small. "2" represents smaller.
"3" represents generally. "4" represents larger; "5" represents very large. It turns the variable operation into "policy advisory effectiveness". As dichotomous variable, the assignment of "small" is 0 . The assignment of "large" is 1 . The respondents have "optimistic tendencies" in such subjective issues. Then, "1" represents very small; "2" represents smaller; "the general 3 " is classified as "small"; "4" represents larger; "the very large 5" is classified as "great". The dependent variable settings and distribution is shown in the following "Table II":

TABLE II. SOCIAL FUNCTION INDICATORS SETTINGS AND DISTRIBUTION

\begin{tabular}{|c|l|l|l|c|}
\hline first grade indexes & \multicolumn{1}{|c|}{ secondary index } & \multicolumn{1}{|c|}{ Yes (big) } & No (small) & total \\
\hline \multirow{3}{*}{ Social function } & Theoretical research & $36.54 \%(19)$ & $63.46 \%(33)$ & $100 \%(52)$ \\
\cline { 2 - 5 } & Social services & $42.31 \%(22)$ & $57.69 \%(30)$ & $100 \%(52)$ \\
\cline { 2 - 5 } & $\begin{array}{l}\text { Policy advisory } \\
\text { effectiveness }\end{array}$ & $65.96 \%(31)$ & $34.04 \%(16)$ & $100 \%(52)$ \\
\hline
\end{tabular}

\section{B. Independent Variables Settings}

In the interviews, we found that there are many problems in the development of the social science mass organizations in Hubei province, including the parasitic development, the imbalance, the lack of funds and manpower, the lag of organizational structure and the imperfections of many social functions. Then, do the stated problems limit the social function of social science mass organizations? We try to further investigate the above factors and summarize the impact of the development mode, development scale, personnel protection and funding support on the social functions of social sciences. Specific operation can be turned into the following variables:

- The development model mainly examines the official dominance in the development of social science mass organizations according to the character of business executive unit. Business executive unit has the official dominance with official or semi-official nature. For some social science mass organizations that take the association of social sciences in Hubei province as the business executive unit, we can find that the affiliated units often provide more help in actual business guidance and resource protection through the interview. Therefore, based on the nature of the affiliated units, the units are considered the have official dominance with the official or semiofficial nature. The operation could be turned into dichotomous variables. The assignment of "yes" is 1 , and the assignment of "no" is 0 .

- The development scale mainly examines the member scale of social science mass organizations. And the operation could be turned into group membership and individual membership. They are continuous variables.

- Personnel protection studies the adequacy of personnel in the day-to-day management of social science mass organizations. And it mainly examines the adequacy through the daily number of managers or whether there is full-time staff. The former is continuous variable, and the latter is dichotomous variable. The assignment of "yes" is 1, and the assignment of "no" is 0 .

- In the term of main source of funding, it mainly examines major funding sources of the daily management and academic research of social science mass organizations. The funding sources are divided into three categories: own revenue and expenditure, including self-financing and dues; government support, including direct government funding and government procurement expenditure; social support, including other types of financial support, corporate sponsorship and charity sponsorship. The operation could be turned into three-category variables. And the assignment of "own revenue and expenditure" is 1, 
the assignment of "government support" is 2, and the assignment of "social support" is 3. Through preliminary analysis, we can find that there are little funds of social support as in "Table III". Therefore, these two variables are manipulated into dichotomous dummy variables in practical research. The assignment of "government support" is 1 , and the assignment of "non-government support" is 0 .
Through the preliminary analysis, the author found that there was significant correlation among various sources of funding ( $\mathrm{p}<=0.001$, significant correlation at 0.001 ). Therefore, we can incorporate one of the models to avoid collinearity of the independent variables and examine the impacts of financial security on social functions.

TABLE III. CORRELATION COEFFICIENT OF VARIOUS Funding SOURCES (PERSON)

\begin{tabular}{|c|l|l|l|l|}
\hline \multicolumn{2}{|c|}{} & \multicolumn{1}{|c|}{$\begin{array}{c}\text { The main source of } \\
\text { subject fund }\end{array}$} & $\begin{array}{c}\text { The main source of } \\
\text { conference expense }\end{array}$ & $\begin{array}{c}\text { The main source of } \\
\text { management fund }\end{array}$ \\
\hline $\begin{array}{c}\text { The main source of } \\
\text { subject fund }\end{array}$ & Pearson correlation & 1 & $.640^{* * *}$ & $.732^{* * *}$ \\
\hline $\begin{array}{c}\text { The main source of } \\
\text { conference expense }\end{array}$ & Significance (bilateral) & & .000 & .000 \\
\cline { 2 - 5 } & Searson correlation & $.640^{* * *}$ & 1 & $.445^{* * *}$ \\
\hline
\end{tabular}

\section{RESEARCH HYPOTHESES}

Based on the above analysis and related research, this paper proposes the following assumptions:

- The theoretical research has been significantly influenced by the development model, development scale, personnel protection and main funding sources of the social science mass organizations. Government-led associations and groups with many members and individual members, many daily managers and full-time staff are more likely to conduct theoretical research on the basis of government support funds.

- Social services have been significantly affected by the development model, development scale, personnel protection and major funding sources of social science mass organizations. Government-led associations and groups with many members and individual members, many daily managers and fulltime staff are more likely to conduct social services on the basis of government support funds.

- The policy consultation has been significantly affected by the development model, development scale, personnel protection and main funding sources of the social science mass organizations. Government-led associations and groups with many members and individual members, many daily managers and full-time staff are more likely to play important role on the basis of government support funds.

\section{THE RESEARCH RESULTS}

The author makes the operation on social functions and development of social science mass organizations. And the binary LOGISTIC regression analysis is used to examine the impact of social development on the social functions. It should control the development history and location factors. And then, it can examine the influence of development mode, development scale, personnel protection and funding guarantee on the social functions of social science mass organizations. Due to the limitations of data sources, it mainly examines the fulfillment of social functions of social science mass organizations in this section. However, we can't see that how important the function is and what factors affect these functions.

"Table IV" shows the impact of various factors on the theoretical research of social science mass organizations. From the results of the study, the whole model passed the significance test $(\mathrm{p}=0.008$, and it's significant at 0.01$)$. However, the factors have no significant effect on the theoretical research. Only the number of group members and the number of daily managers have significant impacts on theoretical research (it is significant at the 0.05 level). It has more group members and the daily managers. And then, it is more likely to conduct theoretical research. Compared with individual members, group members tend to reflect the systematic cooperation within an academic community. And it also could provide broader platform for the development of associations. The more group members would show that the association is more active in subject areas and theoretical research. And the daily management is an important guarantee for the orderly development of corporate affairs. The number of daily managers is often directly related to the business scale of the association, which reflects the vitality of the association. And theoretic research is one of them. The research results partially verify the research hypothesis.

At the same time, the research results show that there is no positive connection among theoretical research of the social science mass organizations and its development history, the nature of associations, basic facilities and funding sources. Government-led associations don't have advantages in theoretical research. The government's financial support isn't a necessary condition for the associations to carry out theoretical research. From the perspective of the odds, the leadership of government and the funding of government may limit theoretical research, which may be administrative drawbacks. 
TABLE IV. The INFLUENCING FACtors of TheORETICAL ReSEARCH OF SOCIAL SCIENCE MASS ORganizations

\begin{tabular}{|c|c|c|c|c|}
\hline & \multirow{2}{*}{$\operatorname{Exp}(B)$} & \multirow{2}{*}{ Sig. } & \multicolumn{2}{|c|}{$\operatorname{EXP}(B)$ 的 $95 \%$ C.I. } \\
\hline & & & lower limit & upper limit \\
\hline The establishment duration & .997 & .922 & .945 & 1.052 \\
\hline Located in the provincial capital & 2.543 & .547 & .122 & 53.224 \\
\hline Government-led type & .493 & .384 & 100 & 2.426 \\
\hline The number of group members & $2.072 *$ & .034 & 1.058 & 4.060 \\
\hline The number of individual members & .637 & .074 & .388 & 1.044 \\
\hline The number of daily managers & $1.697 *$ & .047 & 1.006 & 2.862 \\
\hline full-time staff & .913 & .928 & .128 & 6.534 \\
\hline venue for working & 2.491 & .350 & .367 & 16.888 \\
\hline Meeting funding comes from government support & .438 & .312 & .088 & 2.175 \\
\hline constant (quantity) & .095 & .363 & & \\
\hline
\end{tabular}

"Table V" shows the impact of various factors on the social service functions of social science mass organizations. The results show that the whole model has no significant impact on social services $(\mathrm{p}=0.487$, it didn't pass the significance test). Through the analysis of variables, it found that the leadership of government and the funding of government could increase the possibility of carrying out social services. This study mainly examines the major forms of social services, which mainly included lectures, training and social advocacy. From the perspective of content, lectures, training and social advocacy are often related with social hot spots. And they often make the interpretation of the important principles and policies of the party and the state, and broadcast mainstream culture and values of society. In recent years, social science mass organizations of Hubei province have carried out some social services. For example, the Symposium on the 70th Anniversary of the Victory of the Chinese People's War of Resistance Against Japanese
Aggression and the World Anti-Fascist War, the forum for the development of the "Belt and Road" and the development of state-owned enterprises, the seminars on "supply-side structural reform", the lectures on "Two Studies, One Action", books into campus, lectures on community sports and fitness, insurance lecture, the Publicity Day of insurance, and so on. And it has policy-oriented and grassroots-oriented content. Such activities are often closely connected with the administrative departments of the government and their daily work. And the government can easily provide more financial support.

At the same time, the results show that the development scale, personnel protection and basic infrastructure have no significant effect on the social services of social science mass organizations. For social science mass organizations, many members, full-time staff and workplaces have no significant impacts on increasing the possibility of participating in social services.

TABle V. The Influencing Factors of Social Service of Social SciEnce Mass Organizations

\begin{tabular}{|c|l|l|l|c|}
\hline & \multirow{2}{*}{ Exp (B) } & \multirow{2}{*}{ Sig. } & \multicolumn{2}{c|}{ EXP(B) 95\% C.I. } \\
\cline { 3 - 5 } & & & lower limit & upper limit \\
\hline The established time & 1.012 & .644 & .962 & 1.065 \\
\hline Located in the provincial capital & 2.478 & .560 & .117 & 52.639 \\
\hline Government-led type & $6.040 *$ & .042 & .853 & 42.760 \\
\hline The number of group members & .711 & .211 & .416 & 1.213 \\
\hline The number of individual members & 1.052 & .813 & .690 & 1.605 \\
\hline The number of daily managers & .967 & .731 & .799 & 1.171 \\
\hline full-time staff & 1.366 & .692 & .293 & 6.375 \\
\hline venue for working & .120 & .098 & .010 & 1.480 \\
\hline Management funding comes from the government support & $.057 *$ & .034 & .003 & 1.178 \\
\hline constant (quantity) & 26.728 & .259 & & \\
\hline
\end{tabular}

"Table VI" shows the impact of various factors on policy advisory of social science mass organizations. The results show that the whole model has no significant impact on policy advisory ( $\mathrm{p}=0.283$, it didn't pass the significance test). Various factors have no significant influence on the function of policy advisory. There is no significant difference between the government-led associations and other associations in the role of policy advisory. The funding of the project mainly comes from government support and doesn't increase the possibility of enhancing the function of policy advisory. The development scale of the associations wouldn't affect its policy support. From the view of the odds, larger associations have slightly higher possibilities in the role of policy advisory (coefficient is larger than 1). However, the difference is not significant. The personnel protection and hardware protection of the associations haven't affected the function of the policy advisory. 


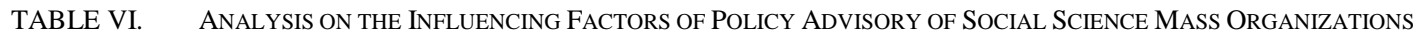

\begin{tabular}{|c|l|l|l|l|}
\hline & \multirow{2}{*}{ Exp $(\mathbf{B})$} & \multirow{2}{*}{ Sig. } & \multicolumn{2}{c|}{ EXP(B) 95\% C.I. } \\
\cline { 3 - 5 } & & & lower limit & upper limit \\
\hline The established time & 1.017 & .575 & .959 & 1.079 \\
\hline Located in the provincial capital & .064 & .227 & .001 & 5.520 \\
\hline Government-led type & .722 & .734 & .110 & 4.723 \\
\hline The number of group members & 1.203 & .537 & .669 & 2.165 \\
\hline The number of individual members & 1.062 & .810 & .652 & 1.730 \\
\hline The number of daily managers & .954 & .663 & .770 & 1.181 \\
\hline full-time staff & .289 & .235 & .037 & 2.248 \\
\hline venue for working & .083 & .120 & .010 & .675 \\
\hline Project funding comes from the government support & 1.361 & .849 & .057 & 32.536 \\
\hline constant (quantity) & 466.568 & .048 & & \\
\hline
\end{tabular}

\section{RESEARCH RESULTS AND DISCUSSION}

It examines the various factors within the associations that may affect their social functions. And then, it has made the following conclusions:

First, the vitality of the association influences the theoretical research of social science mass organizations. Compared to loose individual organizations, good cooperation among the group members is an important guarantee for the social science mass organizations to carry out theoretical research. This also sideways reflects the importance of organization in the development of social science mass organizations. The personnel protection is also an important manifestation of organization in the daily management. Some organizations carry out academic activities, publish necessary social publications, and ensure regular and certain amount of theoretical research activities. And then, the associations can maintain their vitality. To some extent, government intervention may limit theoretical research (although the result is not significant).

Second, the government supports the promotion of social services. Social science mass organizations should not only conduct theoretical research, but also disseminate theoretical research to the general public in an accessible and easy-tounderstand form. The strength of the government administration is to service the grass roots and the public. Therefore, the government-backed associations are also more likely to make progress in the field of social services. The transformation of government functions provides more space for the development of social science mass organizations. In the background of decentralization, the government supports some social science mass organizations through the funding support and policy support. And then, these associations publicize social policies, mainstream values and social culture to the general public. Especially, the social services of government-led social science mass organizations have been developed under this background.

Third, the policy advisory of social science mass organizations isn't affected by the nature and the scale of the social science mass organizations. The social science mass organizations must change their concepts, release their thinking and change their development mode. And then, they could provide quality intellectual support and make further influence on the government decision-making. As the service-oriented government appears, it puts forward higher requirements for government decision-making. The government has faced many think tanks in an open manner. At present, the role of think tanks of social science mass organizations hasn't yet been highlighted. The governmentled associations are closely linked with the government. They have not been able to give full play to the function of policy support. And the government funding has not shown any advantage in enhancing decision-making support of the associations. Under such a relaxed and favorable social situation, social science mass organizations should grasp the opportunity and make full use of resources.

\section{CONCLUSION}

Finally, it should be pointed out that the research on the influencing factors of social function of social science mass organizations is still superficial, and many deep-seated factors have not yet been included. For example, it should understand the level of theoretical research, social services and policy advisory. And it also should realize the influencing factors of social science mass organizations in different levels. In addition to the analysis of the internal factors, social structural factors and external environmental factors have also affected the social functions of social science mass organizations. With the limitation of the condition, the author doesn't make the analysis of these factors.

\section{REFERENCES}

[1] Gu Aihua. Connotation, characteristics and functions of Chinese social science mass organizations [J]. Chinese Administration, 2007 (11)

[2] Xu Jianyuan, Sun Dawei. Analysis on development history of Chinese social science mass organizations [J]. History of the Party, 2008 (1)

[3] Yang Luping, Zhou Zhaoming, Sun Qingguo. Research on management system of Chinese social science mass organizations [J]. Shandong Social Sciences, 2008 (10)

[4] Deng Guosheng. The contribution of China's social organization and international comparison [J]. Chinese Administration, 2006 (3)

[5] Yang Luping. Relevant issues on the scientific development of social science mass organizations in China [J]. Corporate Management Research, 2010 (9)

[6] Shen Jinjian, Zou Qingshan. The connotation of the construction of China's new think tank [J]. Economic Forum, 2015 (11)

[7] Kang Xiaoguang. Chinese associations in the transitional period [J]. China Youth Science and Technology, 1998(10).

[8] Yang Wenbo. Study on the relationship between the development of civil think tanks and the construction of social science mass 
organizations in the transitional period [J]. Journal of Yunnan Socialism Institute, 2014 (2) 